\title{
O QUE PENSAMOS NÓS, FORMADORES/AS DE PROFESSORES/AS, SOBRE FORMAÇÃO DOCENTE EM FILOSOFIA?
}

\section{Patrícia Del Nero Velasco*}

Resumo: Nas últimas décadas, assistiu-se a uma multiplicidade de produções técnicas e bibliográficas sobre/em Ensino de Filosofia. Produções estas que direta ou indiretamente incidem sobre a questão da formação de professores. Embora reconheça a singularidade da experiência filosófica representada (e vivenciada) por cada pesquisador/a da área, assim como a riqueza teórica advinda dos divergentes fundamentos epistemológicos que embasam cada pesquisa, o presente texto consiste em uma tentativa de mapear aspectos comuns aos depoimentos daqueles e daquelas que constituem a própria comunidade acadêmica da área de Ensino de Filosofia no Brasil sobre a seguinte questão: "O que considera fundamental para formar um/a professor/a de Filosofia?". Entende-se que ao dar voz àqueles $e$ àquelas que pensam filosoficamente sobre o ensino $e$ a aprendizagem de/em Filosofia, as linhas que se seguem compreendem, igualmente, um ato político.

Palavras-chave: Ensino de Filosofia; Prática Docente; Formação de Professores.

Resumen: En las últimas décadas ha habido una multiplicidad de producciones técnicas y bibliográficas sobre/en la Enseñanza de la Filosofía. Producciones que por su vez inciden directa o indirectamente sobre la pregunta acerca de la formación docente. Aunque reconoce la singularidad de la experiencia filosófica representada (y vivida) por cada investigador del área, así como la riqueza teórica que surge de los fundamentos epistemológicos divergentes que sustentan cada investigación, el presente texto consiste en un intento de mapear aspectos comunes a los testimonios de quienes constituyen la comunidad académica del área de Enseñanza de la Filosofía en Brasil sobre la siguiente pregunta: "¿Qué consideras fundamental para formar un/una profesor/a de Filosofía?". Se entiende que al dar voz a quienes piensan filosóficamente sobre la enseñanza y el aprendizaje de/en Filosofía, las siguientes líneas igualmente comprenden un acto político.

Palabras claves: Enseñanza de la filosofía; Práctica docente; Formación de profesores.

Toda essa discussão da Filosofia no Ensino Médio, do melhor aproveitamento dos[/as] estudantes de uma educação filosófica, as facilidades $e$ as dificuldades do professorado de Filosofia na lida, no ato pedagógico, passam pela formação.

(Dalton José Alves)

\section{Considerações iniciais}

O presente texto integra uma pesquisa mais ampla da autora que se insere no movimento crescente no Brasil de pensar filosoficamente o ensino da Filosofia - de

\footnotetext{
* Professora associada da Universidade Federal do ABC. Coordenadora do Laboratório de Ensino e Pesquisa em Filosofia - LaPEFil (CNPq/UFABC). Email: patricia.velasco@ufabc.edu.br.
}

refletir sobre a prática docente (em seus vários níveis) e a formação de professores/as a partir do olhar daqueles e daquelas que pesquisam o Ensino de Filosofia em diálogo com a tradição filosófica, seus legados, seus autores e autoras ${ }^{2}$.

\footnotetext{
${ }^{2}$ Mais especificamente, este texto resulta do projeto de pós-doutorado "A constituição do Ensino de Filo-
}

VELASCO, Patrícia Del Nero. O que pensamos nós, formadores/as de professores/as, sobre formação docente em filosofia? Revista Sul-Americana de Filosofia e Educação. Número 34: nov. 2020 - abril 2021, p. 12-33. DOI: https://doi.org/10.26512/resafe.v2i34.35127 
Nesse sentido, as linhas que se seguem compreendem uma tentativa de constituir aspectos comuns às multifacetadas perspectivas de formação docente de pesquisadoras e pesquisadores que assumem o ensino e a aprendizagem de/em Filosofia como objeto de estudo. Mas de quais colegas estamos falando, em um universo de quase 50 programas de pós-graduação em Filosofia e um sem-número em Educação? A pergunta "O que considera fundamental para formar um/a professor/a de Filosofia?" foi enviada para todos os membros do GT da ANPOF Filosofar e Ensinar a Filosofar, grupo de trabalho que congrega, em 2020, 24 pesquisadores/as em seu núcleo de sustentação e 21 no núcleo de apoio ${ }^{3}$. A pretendida análise foi realizada a partir das respostas daqueles e daquelas que colaboraram com a pesquisa no prazo estipulado, em um total de 27 participações ${ }^{4}$.

sofia como campo de conhecimento: mapeamento da área na década de 2008 a 2018", realizado sob a supervisão do Prof. Dr. Rodrigo Pelloso Gelamo, junto ao Programa de Pós-Graduação em Educação da UNESP/Marilia (Chamada CNPq No 22/2018 Bolsas Especiais no País e Exterior; Processo: 148901/2018-2).

3 Para a lista de nomes, cf. $<$ http://anpof.org/portal/index.php/en/gt-filosofar-eensinar-a-filosofar/category-items/37-

filosofareensinarafilosofar-gt/258-participantes $>$. Acesso: 27 fev. 2020.

4 Contribuíram com depoimentos os/as seguintes pesquisadores/as: Alexandre Jordão Baptista (UFMA); Américo Grisotto (UEL); Antonio Edmilson Paschoal (UFPR); Christian Lindberg (UFS); Dalton José Alves (UNIRIO); Dante Augusto Galeffi (UFBA); Edgar Lyra (PUC-RJ); Elisete Medianeira Tomazetti (UFSM); Filipe Ceppas (UFRJ); Flávio José de Carvalho (UFCG); Geraldo Balduíno Horn (UFPR); Gisele Dalva Seco (UFRGS); José Benedito de Almeida Júnior (UFU); Leoni Maria Padilha Henning (UEL); Marcelo Senna Guimarães (UNIRIO); Marcos Antônio Lorieri (Uninove); Marcos de Camargo von Zuben (UERN); Marta Vitória de Alencar (EA/USP); Paula
Integram a análise também as respostas de 14 pesquisadores/as da área que, embora não sejam formalmente vinculados ao GT, possuem produção e orientação na área ${ }^{5} e$, por esta razão, foram convidados a colaborar com a pesquisa em questão ${ }^{6}$.

Quando se trata de cursos de formação de professores/as, sabe-se do "seu histórico desprestígio em relação à formação para a pesquisa, e a classificação de tais cursos como sendo de segunda categoria, no contexto geral das universidades" (TOMAZETTI, 2002, s/p). No caso específico dos cursos de Licenciatura em Filosofia, soma-se a este desprestígio tanto a ignorância dos pares com relação às especificidades da formação docente em Filosofia, quanto a própria dificuldade

Ramos de Oliveira (UNESP); Pedro Ângelo Pagni (UNESP); Pedro Ergnaldo Gontijo (UnB); Roberto Rondon (UFPB); Rodrigo Pelloso Gelamo (UNESP); Silvio Donizetti de Oliveira Gallo (Unicamp); Walter Omar Kohan (UERJ); Wanderley José Deina (UTFPR); Wanderson Flor do Nascimento (UnB).

${ }^{5}$ Especificamente, participaram da pesquisa os seguintes nomes: Alexandre Filordi de Carvalho (UNIFESP), André Luis La Salvia (UFABC), Antonio Joaquim Severino (USP/UNINOVE), Celso Fernando Favaretto (USP), Eduardo Salles de Oliveira Barra (UFPR), Evanildo Costeski (UFC), Felipe Gonçalves Pinto (CEFET/RJ), José Renato de Araújo Souza (UFPI), José Teixeira Neto (UERN), Luizir de Oliveira (UFPI), Maria Cristina Theobaldo (UFMT), Renê Jose Trentin Silveira (UNICAMP), Samuel Mendonça (PUC-Campinas) e Taís Silva Pereira (CEFET/RJ). Cabe mencionar também que as respostas de Barra, assim como de Alves, Ceppas, Kohan, Lyra Netto, Nascimento e Tomazetti, membros do GT, foram obtidas através da transcrição de entrevistas realizadas com os/as pesquisadores/as.

${ }^{6}$ Todos/as os/as participantes são mencionados/as no decorrer do texto, seja no próprio corpo do trabalho, seja em nota de rodapé. A única exceção é Eduardo Barra - a quem peço sinceras desculpas -, cuja entrevista enveredou para outras questões da área $e$ a pergunta-cerne do presente texto acabou não sendo feita. 
daqueles $e$ daquelas que pesquisam $e$ lecionam na área em encontrar pontos mínimos comuns sobre o assunto.

É muito difícil dizer o que é fundamental para formar um[/a] professor[/a] de filosofia. A própria perspectiva filosófica a que se é filiado condiciona a resposta que se dá a essa pergunta. Um[/a] positivista enfatizará uma formação científica, já um[/a] marxista reforçará, talvez a importância da dialética. Um[/a] fenomenólogo[/a] ou um[/a] pós-estruturalista pode enxergar outras prioridades... A melhor formação acadêmica não garante a melhor formação necessária a um[/a] docente. A singularidade da experiência filosófica quando bem vivida, pode inspirar diferentes perfis docentes a promover a transmissibilidade da filosofia com mais ou menos sucesso, que também dependerá dos[/as] interlocutores[/as] que encontrará em sala de aula. A transmissibilidade que nunca é apenas repasse, mas recriação. (Pedro Ergnaldo Gontijo/UnB)

$\mathrm{O}$ presente texto reconhece a dificuldade a que se refere Gontijo, assim como a singularidade da experiência filosófica representada (e vivenciada) por cada colega convidado/a. Ademais, sabe-se que qualquer tentativa de enlaçar posicionamentos de profissionais com referencias teóricos tão distintos pode incorrer em concepção frágil e, como tal, suscetível de críticas mais acentuadas. Não obstante, entende-se que é preferível ensaiar apreciações comuns a deixar de fazê-lo: para além das saudáveis divergências de perspectivas, pontuar os aspectos mais citados pelos/as participantes da pesquisa sobre o que consideram fundamental para a formação docente em Filosofia ${ }^{7}$ não deixa de ser um ato político: dar voz àqueles $e$ àquelas que pensam filosoficamente sobre $\mathrm{o}$ ensino e a aprendizagem de/em Filosofia.

\section{Primeiro aspecto formativo: o ensino de Filosofia como problema filosófico}

Pode-se dizer que grande parte das supramencionadas divergências de perspectivas dos membros do GT sobre ensino de Filosofia e formação docente assenta-se no fato de que são inúmeras as concepções de Filosofia e os modos com os quais cada filósofo/a-educador/a com esta se relaciona. Inevitavelmente a complexidade em precisar o que é Filosofia acaba estendida à identificação do que é ensinar Filosofia e, igualmente, do que é formar para a docência em Filosofia.

Essa situação, por sua vez, acaba incorrendo em um dos consensos do grupo de trabalho em questão: parece-nos que os/as entrevistados/as tendem a concordar com Gallo e Kohan, defendendo que "O professor que não se assume como filósofo não tem a menor chance de ensinar filosofia, assim como o professor que não se reconhece como pesquisador ${ }^{\&}$ não poderá fazer outra coisa do que reproduzir aquilo que outros pensaram, uma marca da antifilosofia" (2000, p. 183, grifos nossos).

Marcos de Camargo Von Zuben (UERN), por exemplo, afirma que a formação do/a licenciando/a deve ser "filosoficamente relevante, que ele[/a] seja

\footnotetext{
${ }^{7} \mathrm{~A}$ ordenação dos aspectos em questão não segue o critério de prioridade, tendo sido adotada apenas em vista do pretendido movimento do presente texto.

${ }^{8}$ Este aspecto será tratado na seção subsequente.
} 
um filósofo[/a], considerando aqui que não se separam as atribuições de filósofo[/a] e de professor[/a] de filosofia, pois do contrário seria quase como reduzir o ensino de filosofia a questões técnicas" 9 .

\section{André Luis La Salvia (UFABC)} corrobora essa visão, considerando fundamental que o/a licenciando/a "seja convidado[/a] a conhecer, problematizar $e$ tomar posição frente as questões fundamentais ligadas ao ensino de filosofia [...], que ele[/a] desnaturalize sua visão da prática docente e que ele[/a] crie o seu modo de dar aula. É preciso inventar um personagem professor, que precisa fazer escolhas didáticas, metodológicas e propedêuticas que são resultado de problematizações filosóficas".

Para Marcelo Senna Guimarães (UNIRIO), a criação desta personagem professor/a a que faz menção La Salvia passa, igualmente, pela

compreensão da relação entre professor[/a] e alunos/alunas; entre mestre e discípulo[/a], de modo que o[/a] professor[/a] compreenda $e$ desenvolva sua própria maneira de ensinar filosofia, que ele[/a] descubra como ele[/a] se apresenta como um filósofo[/a] formador[/a], como um[/a] educador[/a] filosófico[/a], e que tipo de aprendizagens ele[/a] é capaz de promover. Creio que há uma compreensão filosófica dessa relação, filosófica num sentido bastante pessoal, de definição de uma identidade de educador[/a], uma identidade de filósofo[/a]educador[/a], que leva a ser capaz

\footnotetext{
${ }^{9}$ Citações como essa não serão referenciadas segundo a ABNT, pois foram obtidas das respostas mencionadas na seção de abertura deste capítulo, não tendo sido até então publicadas.
}

de promover uma educação filosófica e, portanto, sentir-se efetivamente como um[/a] professor[/a] filósofo[/a], e não apenas um[/a] professor[/a] de filosofia.

Para que a almejada formação do/a professor/a filósofo/a ocorra, "o ponto de partida que os cursos, que têm como objeto ensinar a ensinar filosofia, poderiam assumir seria [...] a problematização da questão 'ensinar filosofia'" (CERLETTI, 2009, p. 62). Uma problematização que "será sempre, evidentemente, uma tarefa filosófica" (CEPPAS, 2004, p. 3549). Daí a posição de Taís Silva Pereira (CEFET/RJ): "E, talvez mais importante [no processo formativo para o Ensino de Filosofia seja] fomentar a ideia de que ensinar Filosofia já é pressupor um modo de filosofar e de pensar".

A perspectiva em questão, sem dúvida, é da grande maioria dos/as consultados/as e pode ser sintetizada nas palavras de Sílvio Gallo (UNICAMP):

Penso que a filosofia traz, intrinsecamente, uma "ensinabilidade"; a relação de ensino, a relação mestre-discípulo é uma constante na história da filosofia. Assim, saber filosofia precisa ser saber ensinar filosofia $e$ saber aprender filosofia. É preciso, pois, envolver a área específica, dos domínios estritamente filosóficos, com a problemática do ensino; em suma, é preciso fazer uma "filosofia do ensino de filosofia" 10 .

${ }^{10}$ Gallo ainda acrescenta: "Por outro lado, o professor de filosofia não pode prescindir dos conhecimentos específicos da área de educação. Ele precisa dominálos e articulá-los com os conhecimentos filosóficos, de forma transversal". Como este aspecto será tratado 
A referida Filosofia do Ensino de Filosofia abarca discussões sobre os fundamentos teóricos e os pressupostos filosóficos do ensino de Filosofia, como o valor formativo desta, a determinação de conteúdos e metodologias, as relações entre Filosofia e História da Filosofia e, de suma importância para o aspecto ora abordado, as diferentes concepões de Filosofia e suas respectivas múltiplas formas de ensino. Uma amostra de exercícios filosóficos que exemplificam e procuram dar densidade reflexiva à Filosofia do Ensino de Filosofia pode ser encontrada na obra Ensino - de qual? - Filosofia: ensaios a contrapelo (VELASCO, 2019) ${ }^{11}$, assinada por vários dos pesquisadores e pequisadoras mencionados no presente capítulo. Para a compreensão d'O ensino de filosofia como problema filosófico, os/as leitores/as podem consultar o livro de mesmo título, de Alejandro Cerletti (2009).

\section{Segundo aspecto formativo: a indissociabilidade entre ensino de Filosofia $e$ pesquisa}

adiante, por ora restringimo-nos a apresentar, na íntegra, a resposta de Silvio Gallo.

${ }^{11} \mathrm{Na}$ apresentação do livro, lê-se: "Os capítulos que compõem o presente volume constituem uma rica amostra de como as discussões sobre ensinar Filosofia permeiam obras clássicas usualmente identificadas com outros temas e problemas filosóficos. Ademais, a indissociabilidade entre a filosofia e seu ensino está também presente nas propostas e nos percursos filosóficos criados por cada autora e cada autor deste livro coletivo, os quais evidenciam e põem em jogo, em alguma medida, a relação que cada professor/apesquisador/a tem com o filosofar e o ensinar a filosofar. Em última instância, a obra constitui-se de possíveis construções do problema filosófico 'ensinar filosofia"” (VELASCO, 2019, p. 16-17).
A necessária problematização filosófica do ensino de Filosofia está intimamente relacionada com outro ponto de concordância dos pesquisadores $e$ pesquisadoras da área, a saber, a impossibilidade de formação e de prática docente destituídas de pesquisa. No excerto anteriormente citado, Gallo e Kohan (2000, p. 183) alertam: para fazer Filosofia (e não meramente reproduzir o já pensado) é preciso que o professor/a se reconheça como pesquisador/a. Sobre o assunto, depõe Felipe Gonçalves Pinto (CEFET/RJ):

[...] sinto falta do reconhecimento do[/a] professor[/a] de filosofia como pesquisador[/a] para sua prática e da sua prática, pesquisador[/a] também das instituições, das comunidades, dos sujeitos envolvidos na sua atuação, ainda que se trate do reconhecimento de uma espécie de pesquisa informal. Reconhecê-lo[/a] como pesquisador[/a] parece ser uma condição para promover o exame crítico e o amadurecimento das formas de ensinar, divulgar e praticar a filosofia.

Nessa seção, portanto, entende-se pesquisa docente em seu sentido mais amplo: a pesquisa acadêmica dos licenciando/as e licenciados/as e, igualmente, a pesquisa dos professores e professoras de Filosofia em seu ofício de dar aula. Logo, o "desenvolvimento de uma postura de pesquisa em relação ao ensino de Filosofia e aos possíveis benefícios formativos dele decorrentes", como prescreve Marcos Antônio Lorieri (UNINOVE), diz respeito tanto à formação inicial quanto à formação continuada dos/as professores/as de Filosofia. 
São muitos os pesquisadores $e$ pesquisadoras que corroboram a ideia em voga. Antonio Edmilson Paschoal (UFPR), por exemplo, acredita que "a formação para o magistério deveria se desprender daquela formação filosófica, contemplando por exemplo os debates sobre o modo como os[/as] filósofos[/as] se ocuparam da questão do ensino em geral e do ensino da filosofia em particular". Wanderson Flor do Nascimento (UnB), por sua vez, é ainda mais enfático, salientando a necessidade de

reflexões sobre as metodologias e as práticas pedagógicas direcionadas ao ensino da filosofia acompanhando TODA a formação e não apenas o espaço das chamadas 'práticas como componente curricular' e do estágio, que possibilite ao[/à] professor[a] em formação a percepção de que pesquisar a filosofia e pensar seu ensino não sejam tarefas necessariamente separadas. (ênfase do autor).

As pesquisas em Filosofia $e$ as reflexões sobre o seu ensino, para Nascimento, além de imbricadas, devem ocorrer dutante todo o processo formativo $e$ não de modo isolado, em disciplinas ou espaços destinados para tal ${ }^{12}$. Semelhante postura assevera Maria Cristina Theobaldo

\footnotetext{
${ }^{12}$ Embora não esteja falando de pesquisa acadêmica propriamente dita, Alexandre Filordi de Carvalho (UNIFESP) atenta para um aspecto correlato ao da pequisa, a saber, o tempo de estudo: "O estudante necessita ter tempo cronológico, psíquico, econômico e social para estudar. Não se aprende Hegel em uma aula sobre Hegel. Não se aprende, a meu ver, sem tempo de estudo. Assim, considero que um professor de Filosofia tenha de ter tempo para estudar a densa formação e a transformação da Filosofia”.
}

(UFMT), ao defender a participação discente em "dispositivos acadêmicos que aliem o processo formativo para a docência $e$ formação do[/a] pesquisador[/a] em filosofia e em ensino de filosofia, estimulando, assim, a inovação de qualidade dos procedimentos e processos de ensino". Ademais, inclui "grupos de pesquisa focados no ensino de filosofia" como uma das condições acadêmicas a serem favorecidas no processo de formação docente.

A fim de viabilizar aquilo que sustenta para a formação discente, a pesquisadora argumenta que, "sobretudo, [...] a formação inicial e continuada dos[/as] professores[/as] de filosofia requer professores[/as] formadores[/as] comprometidos[/as] com a pesquisa e o ensino de filosofia em todas as suas dimensões". Nesse sentido, a formação e o engajamento do/a próprio/a professor/a formador/a estão em pauta. Segundo La Salvia $^{13}$, o não reconhecimento do ensino de Filosofia como área de pesquisa filosófica pelos professores e professoras de Filosofia acaba incorrendo em três perigosas naturalizações:

primeiro, acabam achando que como fizeram doutorado em filosofia estão aptos[/as] a dar aula, ou seja, naturalizam o ensino achando que basta conhecer bem o conteúdo para ensiná-lo ignorando as técnicas $e$ teorias envolvidas nas situações didáticas; segundo, acreditam que para ser um[/a] bom[/a] professor[/a] basta copiar, ou internalizar, boas práticas docentes que observou ao longo da vida e rejeitar práticas ruins, ou seja, naturalizam o ensino a

\footnotetext{
${ }^{13}$ A partir da segunda menção, não serão necessariamente citados os nomes completos e as respectivas filiações dos/as participantes.
} 
partir da cópia irrefletida de boas práticas que vivenciou, e por fim, como pano de fundo dessas duas naturalizações está a mais terrível de todas que é acreditar que ensinar é um dom que se nasce com ele e não uma profissão que envolve técnicas e teorias que são identificáveis, problematizáveis e ensináveis. Desse modo, encontro colegas professores[/as] de filosofia que possuem essas três naturalizações e que portanto não reconhecem as pesquisas de ensino de filosofia, ou as desprestigiam como sendo menores.

Os professores e professoras de Filosofia aos quais faz menção La Salvia são, muitas vezes, credenciados em cursos de Licenciatura na área - o que inviabiliza (ou ao menos dificulta) a visão, por parte dos/as formandos/as, da indissociabilidade entre ensino e pesquisa filosóficos. Américo Grisotto (UEL) em alguma medida sinaliza possíveis caminhos para que o cenário em questão não se perpetue. Para ele,

é de fundamental importância que se abra espaço para o estudo e a pesquisa neste âmbito [do Ensino de Filosofia] na graduação $e$ isto de modo que haja uma linha de pesquisa em filosofia reservada para a relação entre ensino/formação $e$ pesquisa filosófica, de modo a oferecer ao aluno[/a] a alternativa de que sua Iniciação Científica (IC) e Trabalho de Conclusão de Curso (TCC) possam realizar-se nesta área.

E completa, estendendo sua proposta à pós-graduação: "que se batalhe pela inserção de linhas de pesquisas destinadas à relação filosofia e educação $e$, filosofia $e$ ensino, nos Programas de Pós-graduação dos nossos Mestrados e Doutorados stricto senso em filosofia". Ainda sobre a pósgraduação, acrescenta Edgar de Brito Lyra Netto (PUC-RJ):

essa abertura do establishment de pós-graduação para a formação de professores[/as] para o ensino básico e para o ensino de filosofia beneficia a área inteira. Não é um favor que está se concedendo; acho que é a área que se reinventa. Se nós tivéssemos uma tradição consolidada - e, nesse sentido, uma presença político-pedagógica no mundo mais relevante - seria muito difícil [que ocorresse] um fenômeno [político] como esse que estamos vendo. [...] [No Ensino de Filosofia] a filosofia se reconcilia com a Pólis.

A preocupação com "a pesquisa para o ensino e sobre o ensino" e a associação deste trabalho com a publicização da Filosofia e o consequente exercício de sua dimensão política também faz parte do escopo da proposta de Felipe Pinto, com a qual encerramos a presente seção. Diz ele:

parece fundamental criar e ampliar o diálogo entre docentes pesquisadores[/as], incentivar a observação, exercitar a atenção e a escuta, identificar estratégias $e$ dispositivos para poder examiná-los, modificá-los e, por fim, reconhecer o ensino de filosofia como território de riscos, de contingências, e, por isso, mesmo como campo de pesquisa altamente interessante para $\mathrm{o}$ amadurecimento da experiência de liberdade da nossa sociedade.

Terceiro aspecto formativo: o diálogo com o tempo presente - com as outras áreas de 
conhecimento, com a cultura, com o seu público alvo

O desenvolvimento da postura de pesquisa em relação ao ensino da Filosofia e o conhecimento dos debates da/na área permitirá ao/à professor/a em exercício e ao/à futuro/a professor/a não só posicionarse frente às questões centrais, como também "pensar os problemas a partir das relações que ocorrem na imanência da sala de aula" (GELAMO, 2009, p. 107-111).

Estar aberto/a às inquietações, problemas e dilemas adolescentes, assim como dialogar com a cultura $e$ as demais áreas do conhecimento, é uma condição apontada por diversos de nós, formadores/as de professores/as de Filosofia. Roberto Rondon (UFPB) é categórico sobre este aspecto: "mais do que qualquer outro, o desenvolvimento da capacidade de ouvir e incorporar as demandas do(a)s educando(a)s em sua atividade docente para que a filosofia não se torne mais um conteúdo na carga horária escolar" é condição necessária para os cursos de Licenciatura em Filosofia.

A posição supracitada é reiterada por Renê Jose Trentin Silveira (UNICAMP), segundo o qual "o professor de Filosofia precisa estar atento aos anseios $e$ às necessidades desse público ao qual ela se destina, especialmente quando se trata de estudantes das escolas públicas. Precisa saber ouvi-los e dialogar com eles[/as], a fim de que o trabalho filosófico em sala de aula tenha de fato um sentido concreto". Para o pesquisador em questão, trata-se de uma condição para que a Filosofia possa "estar presente na escola para que o povo dela se aproprie e se beneficie e, em contrapartida, para que dessa apropriação resulte também, dialeticamente, o revigoramento da própria filosofia".

O diálogo com o público-alvo tornase, na visão dos/as pesquisadores/as da área, imprescindível para que, nas palavras de Samuel Mendonça (PUC-Campinas), "a filosofia faça sentido para a vida dos[/as] estudantes". E - prossegue -, "para isto, o[/a] professor[/a] de filosofia precisa ser estimulado[/a] desde cedo a pensar os problemas do mundo e do homem. Um[/a] professor[/a] de filosofia deve ser capaz de, por meio da filosofia, pensar os problemas do mundo".

Edmilson Paschoal sinaliza na mesma direção: a formação docente "poderia considerar o modo como a filosofia dialoga com o seu tempo, as fontes que utiliza e o modo como dialoga com as ciências, cultura e educação em cada época". O leitor e a leitora poderiam questionar: mas por que precisaria, o/a professor/a de Filosofia, ser capaz de pensar e dialogar com as problemáticas contemporâneas? Responde Renê Silveira:

Precisa [...] estar atento aos problemas e às temáticas contemporâneas para ajudar esses[/as] estudantes a pensar $e$ a se posicionar sobre elas. Por exemplo, a questão da mulher e do feminismo. Hoje já se discute o apagamento das mulheres da história da filosofia e a importância de se recuperar a contribuição que elas deram a essa área. A maioria dos livros didáticos, porém, praticamente não as menciona. Ora, essa é uma lacuna que o[/a] professor[/a] pode e deve preencher. 
Outra questão é a do racismo na filosofia $e$ a do apagamento da filosofia africana. Quantos filósofos[/as] europeus ajudaram a forjar ideologias racistas? Por que não se estuda autores[/as] africanos[/as]? Não há filosofia na África? Enfim, questões como essas - da participação das mulheres e dos negros na filosofia tocam diretamente os[/as] estudantes do ensino médio e, além de serem essenciais para sua formação, podem também se converter em fator de interesse para o estudo da Filosofia.

O alerta de Trentin é corroborado por José Benedito de Almeida Júnior (UFU), o qual, ao discutir a questão, salienta a implicação das reflexões dessa natureza com a prática da alteridade: "diversidade de gênero, de raça, de religião, de patrimônio cultural e linguístico. Trata-se de um momento de intersubjetividade em que os[/as] docentes devem ser os[/as] primeiros[/as] a darem exemplos de tolerância e respeito à diversidade de modos de ser $e$ de modos de compreender o mundo".

Ou ainda, nas palavras de Rondon, a formação sob a égide da alteridade permite o almejado "trabalho que respeite a diversidade regional, suas questões, e o desenvolvimento das crianças e jovens". Para ele, trata-se de uma formação que requer, "além de uma formação interdisciplinar que contemple conhecimentos da área, [que] esse[/a] profissional tenha conhecimentos de história, sociologia, da educação e das artes do Brasil, além da psicologia da educação". O conhecimento da realidade brasileira (e de suas especificidades regionais) é mencionado por diversos/as colegas e pode ser sintetizado nas palavras de Evanildo Costeski (UFC):

Não se pode filosofar no Brasil sem o conhecimento de nossa história, principalmente de nossas mazelas políticas e sociais. A filosofia deve refletir a vivência dos[/as] alunos[/as] a qual, por sua vez, reflete a realidade brasileira atual. [...] [A Filosofia] é evidentemente Universal, mas nem por isso deixa de ser particular, ou seja, encarnada em determinada realidade histórica.

Por todas essas razões, defende Elisete M. Tomazetti (UFSM) que os cursos de Licenciatura devem incluir "processos formativos [...] que tenham um caráter de abertura, de reconhecimento para as questões regionais, culturais, de gênero; questões étnicas, enfim, abertura para filosofias que ficam fora do cânone, que são marginais". Assim sendo, a prática do almejado diálogo com o tempo presente com as outras áreas de conhecimento, com a cultura, com o público alvo - requer "formação filosófica, formação educacional, política e cultural" (Tomazetti).

\section{Quarto aspecto formativo: ensinar Filosofia requer uma relação viva $e$ intransponível com o filosofar}

Parte dos pesquisadores $e$ pesquisadoras da área defendem que o diálogo (seja no processo formativo, seja em sala de aula) com as demais áreas do conhecimento, com a cultura e com os/as discentes - enfim, com o tempo presente relaciona-se com outro aspecto fundamental da formação filosófica, a saber, a relação pessoal que cada um vivencia com o próprio 
filosofar. Segundo Antônio Joaquim Severino (USP/UNINOVE):

Para se formar como professor[/a] de filosofia, o fundamental é amadurecer a experiência do filosofar, entendido este como construção sistemática dos sentidos da existência. Um amadurecimento intelectual que vá além de uma performance lógicoformal, desenvolvimento de uma sensibilidade que mobilize todos os recursos da consciência subjetiva humana. Um pensar sobre o mundo real, sobre a realidade histórica concreta, em íntimo e fecundo intercâmbio com as outras modalidades de abordagem dessa realidade. [...] O nosso diálogo com os textos deve ser também, e fundamentalmente, um diálogo com o contexto, entendido este como a realidade multifacetada do existir que envolve o[/a] pensador[/a].

Deste modo, embora pesquisadores e pesquisadoras da área defendam o diálogo com a literatura filosófica como imprescindível à formação docente, há que se preocupar também (como explorado na seção precedente) com o contexto, experienciando o filosofar de forma significativa e fecunda tornando a Filosofia, um modo de vida. "Em uma palavra", afirma Pedro Pagni (UNESP), a formação em Filosofia não pode prescindir da "experiência... o de-curso de uma vida dedicada a formar um ethos filosófico e um modo de vida que se expõe ao mundo, preparando-se para a impreparável arte de ensinar, de estar aberto ao que vem de outrem, de se mobilizar e de caminhar com esse outro de si".

Entende-se, assim, que no Ensino de Filosofia "é possível pensarmos em unir esse saber, a Filosofia pensada, à experiência de vida, de onde brotam problemas, campos problemáticos" (TOMAZETTI, 2012, p. 245). Nessa perspectiva formativa que Paula Ramos de Oliveira (UNESP) chama de "Uma relação viva, verdadeira e íntima com a filosofia e com o filosofar", toma-se "a filosofia como algo vivo, dinâmico, um tipo de pensamento que se faz no debate constante da filosofia consigo mesma e com o mundo que a cerca" (Paschoal). Ou ainda: "A Filosofia [...] no sentido de ser no mundo, ser no mundo muito encarnado, cheio de afeto, de força, causalidade etc." (Lyra Netto). Neste sentido, acredita Luizir de Oliveira (UFPI) "que o[/a] professor[/a] de filosofia deve [...] não apenas dominar os 'conteúdos' filosóficos, mas desenvolver uma prática formadora que demonstre que filosofar significa aprender a viver antes de tudo!".

Torna-se preciso, pois, ter $e$ desenvolver nos/as discentes "uma disposição [...] para pensar o tempo presente, reorientá-lo e oferecer-lhe um outro sentido que potencialize a vida, suplantando os limites do pensamento metafísico e da cultura que procuram renunciá-la" (PAGNI, 2004, p. 227). Afinal, lembra-nos Paschoal, "a Filosofia, desde os gregos, sempre foi vinculada à vida: [...] tão logo os gregos se apropriavam de um conhecimento, logo o viviam. Essa memória da Filosofia é que às vezes parece se perder $e$, justamente por isso, acredita-se, às vezes, que o ensino de Filosofia deveria se separar da Filosofia ('pura' - sic)".

$\mathrm{Na}$ contramão do pensamento disseminado na academia, denunciado por Paschoal, pondera Flávio José de Carvalho (UFCG): 
compreendo que o elemento fundamental na formação de um[/a] professor[/a] de Filosofia diz respeito à construção do auto reconhecimento que estudar, pesquisar, ensinar Filosofia parte do exercício pessoal de filosofar, dizendo de outro modo, construir uma postura de filósofa(o)-docente. [...] A discussão e a mobilização de criação de metodologias para o ensino de Filosofia é importante, todavia, tais atividades terão pouco efeito - didático e filosófico, sobretudo - se os sujeitos pedagógicos não se imiscuem com o movimento de pensar, de questionar, de construir compreensões (conceitos) acerca das questões (problemas) que constituem suas vivências corporais, existenciais, intelectuais, sociais $e$ políticas.

A perspctiva de Carvalho é, sem dúvida, a de muitos/as de nós, os/as quais exercem o ofício docente de modo singular $e$ imbricado às vivências pessoais e, portanto, ensinam filosofia $e$ a filosofar também $-e$ quiçá primordialmente - pelo exemplo.

\section{Quinto aspecto formativo: boa formação} filosófica, conhecimento profundo de Filosofia

A vinculação da Filosofia à vida em nada impede que praticamente todos/as os/as participantes tenham mencionado como fundamental para a formação docente em Filosofia "Uma formação filosófica consistente" (Alexandre Jordão Baptista/UFMA) ou, nas palavras de Lorieri, "conhecimento o mais profundo $e$ abrangente possível dos conteúdos da Filosofia". Theobaldo também salienta este aspecto, esmiuçando seu significado:
"Adquirir sólido conhecimento tanto da tradição filosófica $e$ de seus temas $e$ enfoques contemporâneos, quanto conhecimento dos processos de interpretação e de elaboração discursiva típicos da filosofia".

O ponto em questão - nos termos de José Teixeira Neto (UERN), a "boa formação na cultura filosófica" - parece pacífico, pois, como afirma Gisele Dalva Secco (UFSM), "Ninguém pode ensinar o que não sabe". Algumas e alguns de nós, como Paschoal, ainda defendem que:

A base filosófica de sua formação deve permitir a ele[/a] não apenas ter um "conteúdo" a ser repassado aos seus alunos[/as], mas também saber pensar filosoficamente, nas palavras de Salma Tannus Muchail (PUC-SP), a capacidade de ler filosoficamente textos filosóficos $e$ textos não filosóficos. Acrescentaria, de ler filosoficamente formações discursivas e extra-discursivas (Foucault).

Assim sendo, esse conhecimento filosófico profundo (por meio da literatura filosófica) e abrangente (dado o públicoalvo, um/a professor/a apenas especialista pode vir a ter dificuldades) envolve, igualmente, a apropriação do modo filosófico de leitura, de escrita $e$ de reflexão ${ }^{14}$. Portanto, para Marta Vitória de Alencar (Escola de Aplicação/FE-USP),

Quando se pensa numa formação filosófica o que está em jogo são as habilidades do pensar filosoficamen-

\footnotetext{
${ }^{14}$ Para Wanderley José Deina (UTFPR), é fundamental à formação do/a professor/a de Filosofia "o interesse pela formação de sujeitos pensantes desde a Educação Básica”.
} 
te, que é diversa em cada (sub)área da Filosofia. Ora, do[/a] professor[/a] de filosofia se exige a compreensão de como modalidades filosóficas de reflexão podem ser abordadas $e$ atravessadas por um mesmo problema, a saber, o filosofar, isto é, a atividade mesma de pensar filosoficamente na diversidade de filosofias e modalidades filosóficas, na diversidade de metodologias filosóficas $e$ problemas filosóficos [...].

O fomento das "habilidades do pensar filosoficamente" que constituem os modos filosóficos de leitura, de escrita e de reflexão é uma preocupação do grupo de pesquisadores/as que já é expressa no próprio nome do GT, grafado no infinitivo: filosofar e ensinar a filosofar. E, em certa medida, relaciona-se com uma determinada postura (inquieta) e com um insistente exercício (de interrogação e sistematização). Os licenciandos e licenciandas devem entender:

que ensinar filosofia implica mais do que levar os alunos a conhecer Filosofia, mas inscrever a Filosofia como experiência de pensamento. Lembrando Deleuze, que a disciplina possa promover pragmaticamente uma "orientação no pensamento" através do assunto-filosofia como condição para que ela seja relevante na formação, como exercício contínuo da dúvida, da formulação de interrogações, de formalização das inquietações intelectuais. (Celso Fernando Favaretto/USP)

A compreensão pelos pares do filosofar como exercício e experiência do pensamento, ao contrário do que se poderia supor, não prescinde da imersão na literatura filosófica; apenas propõe que se estabeleça com esta última uma relação de outra natureza, a saber, uma relação dialógicoreflexiva.

Que os textos clássicos da Filosofia constituem base para a reflexão e o debate filosóficos, é uma conclusão incontestável, sobretudo na fase da formação. O texto tem uma inquestionável dimensão pedagógica. A familiarização com a abordagem sistemática dos textos com vistas a uma leitura consistente é mediação valiosa no processo formativo. O contato e o convívio com textos de boa qualidade nos permitem evitar de cairmos no mero opinionismo do senso comum ou na literatice de consumo. O trabalho do conceito é um esforço necessário para que não predomine, no espírito dos iniciantes, um certo sentimentalismo, tendência sempre presente quando se pretende debater questões que têm a ver com as condições da existência dos seres humanos. Não se trata de ser tolerante com opiniões idiossincráticas. Mas nada disso autoriza a que se tome um texto como uma peça autônoma, autossuficiente, como se ele não fosse o veículo da discussão de uma problemática objetiva, que vai além da trama textual. A abordagem do[/a] filósofo[/a] até pode apoiar-se na abordagem do[/a] filólogo[/a] ou do[/a] linguista, mas ela é diferente. O objetivo da formação filosófica bem como da atuação do[/a] filósofo[/a] é sempre a prática da reflexão filosófica, reflexão que precisa ter como conteúdo os temas/problemas gerais relativos ao todo da existência humana, mediados pelos temas específicos da experiência vivenciada nos diversos âmbitos de nosso existir. (Antônio Joaquim Severino) 
De forma mais sintética, Luizir de Oliveira reitera a posição de Severino e dos/as demais colegas de área: "Precisamos, no caso da Filosofia, conhecer a sua história, trabalhar com os grandes temas e problemas com que ela se depara desde seu nascedouro, compreender como ainda podemos dialogar com pensadores e pensadoras que, embora distantes no tempo e no espaço, seguem oferecendo alimento para nossa reflexão". Tem-se, pois, que para os/as pesquisadores/as formadores/as de professores/as, os conhecimentos de Filosofia (incluindo a apropriação dos modos filosóficos de leitura, de escrita e de reflexão) são imprescindíveis à formação docente na área - substancial matéria prima para pensarmos as nossas próprias questões.

Sexto aspecto formativo: boa formação filosófico-educacional - conhecimento de metodologias e práticas de ensino (de Filosofia)

$\begin{array}{crr}\text { Além } & \text { dos supramencionados } \\ \text { conhecimentos de Filosofia, os }\end{array}$ pesquisadores e pesquisadoras da área defendem como crucial aos/às futuros/as docentes o conhecimento de metodologias $e$ práticas de ensino - ou "habilidades didáticas [...] para tornar esses conteúdos acessíveis aos estudantes" (Trentin) -, atentando para os diferentes níveis da educação escolar. Nas palavras de Theobaldo, os licenciandos e licenciandas devem "conhecer procedimentos pedagógicos específicos para o ensino e o aprendizado do saber e da reflexão filosóficos em sala de aula e de acordo com o nível de ensino". Sobre os conhecimentos pedagógicos específicos para o Ensino de
Filosofia, detalha Almeida Junior (grifos nossos):

Acredito que a nossa principal função como formador[/a] de professores[/as], deste ponto de vista é, proporcionar às turmas um repertório de recursos metodológicos de seleção e organização dos conteúdos (plano de curso); seleção $e$ organização de instrumentos de avaliação condizentes com as ciências humanas em geral e com a filosofia, em suas diversas áreas, especificamente. Concepção quantitativa e qualitativa de preparação do curso, preparação das aulas, sistemas de avaliação. Quando priorizamos a formação tendo em vista oferecer um repertório de possibilidades metodológicas e de conteúdo damos aos futuros professores e professoras inúmeras possibilidades de ação tendo em vista as circunstâncias concretas de cada escola, ou de turmas na mesma escola ou ainda mesmo em níveis diferentes, como experiências no ensino fundamental ou no ensino superior seja em cursos de filosofia seja como docentes de filosofia em outros cursos, como Direito, Administração, Pedagogia.

$\mathrm{Na}$ perspectiva dos/as pesquisadores/as da área, o conhecimento profundo de Filosofia, anteriormente mencionado, embora necessário, não é suficiente para a boa formação do/a professor/a de Filosofia. Faz-se necessário, como afirma Zuben, "que sua formação seja metodologicamente forte, propiciando a capacidade de transpor sua perspectiva filosófica em propostas didáticas coerentes $e$ eficientes quanto aos objetivos estabelecidos". Certamente um diferencial 
relevante com relação à formação do/a Bacharel, demandando - nas palavras de Flor do Nascimento - "um contato mais intenso com os usos das tecnologias em pesquisa e ensino, do que estamos habituados nas pesquisas filosóficas".

Os supracitados conhecimentos de metodologias e práticas de ensino de Filosofia não são o único diferencial da formação do/a licenciando/a. Teixeira, por exemplo, pensa que "a licenciatura deve propiciar a compreensão dos problemas educacionais que envolvem a formação dos[/as] jovens na escola, como conhecimentos pedagógicos e educacionais específicos". José Renato de Araújo Sousa (UFPI) considera "a didática e a dedicação à Educação como fator importante para se formar um[/a] bom[/a] professor[/a]". Rondon faz coro aos colegas, defendendo que haja "o estímulo ao conhecimento da docência como profissão $e$ suas especificidades na sociedade brasileira". Um aspecto formativo sobre o qual já nos alertara João Cruz Costa (1959, p. 115) cerca de sessenta anos atrás: "por melhores que possam ser os programas [de formação docente], por mais enfeitados que sejam, nada se fará se o professorado não possuir uma base sólida de preparo e consciência clara do seu trabalho".

Sétimo aspecto formativo: integralidade da
Licenciatura com relação ao Bacharelado Embora haja uma ou outra voz contrária $^{15}$, a grande maioria de nós,

15 Gisele Dalva Secco (UFSM) é uma das pesquisadoras que discorda do ponto aqui tratado, afirmando: "Há uma falsa dicotomia em nossos debates sobre isso, estampada no jargão da 'bacharelização das licenciaturas'. Um bom professor formadores/as de professores/as, enxerga dadas as especificidades do trabalho docente - que os cursos de licenciatura deveriam ter integralidade própria com relação aos respectivos bacharelados. Não obstante conste nas Diretrizes Curriculares Nacionais para a Formação de Professores da Educação Básica ${ }^{16}$, a integralidade dos

precisa ser um bom bacharel e, en plus, receber uma formação na qual estude um bom bocado de psicologia (e não somente psicologia da educação, que ninguém vai longe sem Freud nível 1), alguma sociologia e antropologia - alguma quer dizer, um curso de cada - e sobretudo tenha cursos nos quais possa experimentar lecionar". Como será explorado nessa seção, para os/as demais pesquisadores/as da área, a formação pedagógica não pode ser compreendida como um "en plus", uma vez que é imbuída da reflexão filosófica - constituindo-se, portanto, de uma formação filosófico-pedagógica (e não de um mero complemento à formação filosófica). Já Severino, embora- como Secco - esteja nas palavras dele "remando contra a corrente", o faz por razões distintas: "Até hoje continuo achando que não se devia separar a área de ensino de... da área do conhecimento correspondente. Entendo que essa separação só reforça a indevida oposição entre o campo educacional e o campo científico, como se marca na distinção entre Licenciatura e Bacharelado. Minha visão quanto a isso é de que precisaríamos integrar num único processo pedagógico as formações do[/a] docente, do[/a] especialista e do[/a] pesquisador[/a]. Sei que talvez esteja remando contra a corrente, mas penso sinceramente assim, em que pesem os dados contrários da realidade brasileira, na qual sempre esteve presente esse conflito entre Bacharelado e Licenciatura. Sempre sonhei que pudesse haver um curso de graduação na área, articulando as três perspectivas, em todas as áreas de conhecimento, sempre com a fundamentação alicerçante numa prática investigativa do campo específico". Dessa forma, a proposta de Severino parece ser outra: a formação integral do/a docenteespecialista-pesquisador/a.

${ }^{16}$ Cf. Parecer CNE/CP 09/2001 (BRASIL, 2002): "a Licenciatura ganhou, como determina a nova legislação, terminalidade e integral idade própria em relação ao Bacharelado, constituindo-se em um projeto específico. Isso exige a definição de currículos que não se confundam com o Bacharelado ou com a 
cursos de Licenciatura Plena ainda está distante de ser realidade em algumas instituições de ensino superior, como constata Christian Lindberg Lopes do Nascimento (UFS):

Entre a legislação e a prática têm um hiato gigantesco. A legislação indica que os estudantes de Filosofia precisam ter disciplinas técnicas (nos autores ou nos temas filosóficos), há uma carga destinada às práticas de ensino e estágio. Mas quando você vai para a graduação... [...] Aos poucos os[/as] alunos[/as] estão percebendo essa discrepância, entre o curso ser uma licenciatura e a prática [instaurada de] "formar" um[/a] bacharel. [...] Agora falta estreitar o que está na lei com o que está no currículo da licenciatura em Filosofia.

Geraldo Balduíno Horn (UFPR) é um dos ferrenhos defensores da integralidade dos cursos de Licenciatura em Filosofia, por ora apenas garantida por lei em parte das instituições de ensino superior do país ${ }^{17}$.

Entendo que para formar um/a professor/a de Filosofia é necessário, antes de tudo, ter um curso de Licenciatura com nome e sobrenome próprios. Hoje a maioria dos cursos de graduação de Filosofia possui as modalidades de bacharelado $e$

antiga formação de professores que ficou caracterizada como modelo ' $3+1$ '.'

${ }^{17}$ Há que se ponderar que, a despeito da crítica feita aqui aos diversos cursos de Licenciatura em Filosofia que não atendem aos preceitos formativos defendidos pelos pesquisadores e pesquisadoras da área de Ensino de Filosofia, na última década foram criados cursos bastante atentos aos preceitos em questão, assim como inúmeros outros passaram por revisões de seus projetos pedagógicos, aproximando-se daquilo que é fundamentado na literatura da área. licenciatura. Em si não haveria problema se fosse possível romper a dicotomia estrutural presente nessa forma de organização. Dicotomia essa que se acentuou (mais recentemente) com o investimento $e$ ampliação dos cursos de pósgraduação stricto sensu em Filosofia. A partir daí, passa a existir, conscientemente, uma maior valorização $e$ investimento na formação de bacharéis (formação mais rápida, normalmente de três anos) e voltada à preparação de candidatos ao stricto sensu (mestrado e doutorado). Um círculo vicioso e de reprodução.

Soma-se ao histórco desprestígio dos cursos de formação de professores $e$ professoras a estrutura organizacional mencionada por Horn, na qual as graduações não são vistas com finalidade própria, mas entendidas como portas de acesso à pós-graduação. Considerando que os mestrados e doutorados acadêmicos não têm linhas de pesquisa em Ensino de Filosofia e que os mestrados profissionais são recentes (com início a partir de 2015), a estrutura acadêmica acaba alimentando o "círculo vicioso e de reprodução": os bacharelados são valorizados em detrimento das licenciaturas por formarem os/as futuros/as mestrandos/as e doutorandos/as; a existência da pós-graduação, nos moldes hoje consolidados, requer que se atente à formação do bacharel. Situação que não deixa de ser também problemática, pois, para Christian do Nascimento, "é uma ilusão achar que o[/a] bacharel em Filosofia, quando terminar seu doutorado, não vai ser também professor[/a]. Vai trabalhar com o que?". 
No caso específico da formação do/a licenciando/a, contudo, o espaço em que possivelmente exercerá seu ofício - a escola - deve ser estudado e discutido durante a formação universitária. A integralidade dos cursos de Licenciatura passa, portanto, pela oferta de "disciplinas que tratem da escola, dos[/as] alunos[/as] e dos processos de ensinar e aprender. Psicologia, Sociologia, História, Antropologia - da Educação" (Tomazetti). Os estudos e as reflexões sobre Educação e Escola são imprescindíveis à formação do/a professor/a de Filosofia, os quais, "aliados com a presença nossa, professores[/as] e alunos[/as], na escola, [contribui para o] acompanhamento da vida escolar em sua complexidade [e, igualmente, fomenta a] relação rica entre universidade e escola" (Tomazetti).

Ademais, ainda que cada vez mais cursos de licenciatura atentem às exigências legais e formativas de incluir disciplinas pedagógicas e práticas de ensino durante todo o curso, para Horn,

pouco importa a forma como a oferta se dá, é a concepção e a intencionalidade que definem o direcionamento da formação". E ambas são prejudicadas pela formação e experiência dos/as próprios professores/as formadores/as "que atuam nos curso mistos bacharelado-licenciatura [e] não fizeram curso de licenciatura, mal conhecem a realidade escolar $e$ por isso valorizam mais, pasmem, a "filosofia pura".

Há que se rever, pois, as concepções $e$ objetivos formativos daqueles $e$ daquelas que atuam nos cursos de Licenciatura (e não somente nas disciplinas consideradas pedagógicas), de tal modo que a formação docente em Filosofia seja valorizada em todas as suas dimensões. Um passo fundamental para que, como almeja Leoni Maria Padilha Henning (UEL), nosso licenciando "se sinta um[/a] 'filósofo[/a]' e, igualmente, um[/a] 'professor[/a]' vinculado[/a] a um projeto maior de sociedade, para além das suas aulas bem preparadas, para além da sala e das fronteiras da escola com a comunidade onde ele[/a] se insere com sua expertise".

\section{Oitavo aspecto formativo: dimensão prática desde $o$ inicio e durante toda a formação}

A integralidade dos cursos de licenciatura acima discutida é embasada, igualmente, em outra característica definidora do ofício docente, a saber, o caráter prático deste ofício. Pode-se dizer que este ponto é unanimidade entre os/as colegas de GT, visto que constou na maioria das respostas dadas $e$, igualmente, não houve qualquer manifestação em contrário. Afirma Horn:

Penso que os cursos deveriam ser orientados por uma concepção filosófica e pedagógica que levasse às últimas consequências o processo didático-pedagógico necessário para a formação filosófica dos[/as] estudantes que frequentam a educação básica, em especial, o ensino médio. Os programas (e as aulas) do curso de licenciatura em Filosofia deveriam ser pensados $e$ organizados em estreita, mútua, profunda e orgânica ligação com o "chão da escola".

A valorização do chão da escola torna-se imprescindível à formação docente, 
uma vez que é o palco de atuação do/a professor/a. Para Flor do Nascimento,

a formação de um[/a] professor[/a] de filosofia deveria estar atenta à experiência que a escola espera da filosofia, incluindo a problematização dos lugares da experiência para o fazer filosófico e a compreensão da própria história da filosofia. Isso implica em perceber bem o funcionamento dos espaços escolares e suas demandas, entender as possibilidades $e$ limites da presença da filosofia no espaço escolar.

A apropriação de inúmeras teorias sobre o ensino e a aprendizagem em Filosofia é certamente insuficiente para o/a futuro/a docente, o/a qual precisa, além das problematizações em questão, ter algum preparo prévio de sua profissão. Faz-se necessário, pois, "Vivenciar práticas docentes em ambiente educacional (escolas e afins) durante todo o percurso da formação do[/a] futuro[/a] professor[/a]" (Theobaldo).

As práticas docentes às quais faz menção Theobaldo incluem, como atenta Marcelo Senna Guimarães (UNIRIO), "a compreensão das condições de trabalho na escola". Diz ele:

Percebe-se que muitos[/as] jovens professores[/as] levam um certo tempo até compreender como devem se portar na escola, o que é esperado e cobrado deles[/as], e o que eles[/as] podem oferecer de fato. [...] Essa compreensão das condições de trabalho tem diferentes dimensões, [...] incluindo aí as características do ambiente discursivo: que tipo de linguagem ele[/a] deve falar, que "nível" de linguagem, como se comunicar com os[/as] alunos[/as] de modo a se fazer entender $e$ a propiciar uma aprendizagem em filosofia, como se comunicar com professores[/as], direção e outras instâncias e sujeitos trabalhadores da educação, de modo a fazer seu trabalho ser compreendido e reconhecido, podendo gerar resultados observáveis e apreciáveis, ainda que não necessariamente mensuráveis pelos exames externos de avaliação da educação.

Guimarães salienta que além da dimensão discursiva das condições de trabalho na escola, a formação do/a futuro/a professor/a deve incluir o exercício de determinadas práticas docentes que não se restringem à sala de aula, tais como a produção de "produtos didáticos e educacionais diversos, [...] planejamentos, materiais de curso, avaliações, relatórios etc.".

Para tanto, sinaliza Rondon, "Os cursos devem elaborar espaços de estágio $e$ aprendizagem que sejam colocados como centrais e não simplesmente horas a serem preenchidas por obrigação legal". Por exemplo, "o[a] estudante poderia trabalhar em oficinas de produção de material didático e de ensaio de atividades acadêmicas, o que culminaria em sua 'prática de ensino' em sala de aula" (Edmilson). Ou, como sugere Secco, deveria haver espaço para que os/as estudantes se questionassem: "E seu tivesse que transmitir/traduzir o que aprendi [de Metafísica e Filosofia Política] para uma turma de adolescentes no ensino médio, ou de adultos em uma turma da EJA, ou de crianças no $6^{\circ}$ ano? Como e por que o faria? Daria as mesmas aulas?". 
Em suma, os pesquisadores $e$ pesquisadoras da área consideram imprescindivel que a formação "seja acompanhada de experiências de ensino de modo regular e efetivo junto aos possíveis campos de trabalho docente" (Zuben). Grisotto vai além, propondo que "haja, por parte dos[/as] pesquisadores[/as] das outras áreas dos Departamentos de Filosofia, um esforço no sentido de oferecerem aos[às] graduandos[/as] subsídios de suas áreas de modo a fomentar o seu ensino na educação média. Isto é, que destinem as atividades práticas de suas disciplinas para esta finalidade". Afinal, como nos lembra Silveira, "Ninguém sai pronto do curso de licenciatura, embora a qualidade desse curso não seja irrelevante na formação profissional" ${ }^{18}$.

\section{Demais aspectos formativos}

Os oito pontos acima elencados são aqueles que foram recorrentes nas respostas dadas pelos/as professores/aspesquisadores/as da área de Ensino de Filosofia à pergunta "O que considera fundamental para formar um/a professor/a de Filosofia?". Outros aspectos, contudo, também foram assinalados, mas em número menor. Dentre eles, cabe mencionar o papel formativo da Filosofia e de seu ensino, a abertura à alteridade e a necessidade de aprimoramento contínuo. Comecemos por este último ponto.

\footnotetext{
${ }^{18}$ Dalton José Alves (UNIRIO) concorda com Silveira, sustentando que "Os cursos de Filosofia habilitam para um contato com os fundamentos teóricos e metodológicos da área, mas a formação profissional se dá na prática".
}

Sabe-se que o aprimoramento da formação inicial não é prerrogativa da profissão docente. Contudo, dada a mudança constante na legislação educacional, nas estruturas escolares, no comportamento de cada geração, na cultura em geral etc., assim como o número crescente de pesquisas e produções na área e a necessidade do/a professor/a de pensar a própria prática, faz-se necessário "que o[a] professor[a] busque aprimorar-se continuamente, dando seguimento à sua formação" (Silveira). E, quiçá, permitindo "que a experiência da educação seja uma experiência formativa de si mesmo, de forma crítica e criativa" (GALLO; KOHAN, 2000, p. 196).

Daí a importância dos programas institucionais de formação (inicial e) continuada de professores, os quais requerem, como mencionado no segundo aspecto, "professores[/as] formadores[/as] comprometidos com a pesquisa e o ensino de filosofia em todas as suas dimensões" (Theobaldo). Professores e professoras que, para muitos/as de nós, devem manter uma postura dialógica e aberta à alteridade. Nesse sentido, como expõe Dante Augusto Galeffi (UFBA),

Seria preciso pensar outras formas de trabalho na formação, como a prática dialógica viva $e$ o incentivo ao desenvolvimento de um filosofar próprio e apropriado [...]: [para] que [o/a discente] tenha acesso à formação canônica em filosofia $e$ que a partir daí escolha a sua inserção na práxis docente por meio de um pensar conjugado e de uma abertura dialógica fundamental para a investigação infinita. 
A Filosofia como construção dialógica é um tema presente na literatura da área. Em $O$ ensino de filosofia como problema filosófico, Cerletti (2009, p. 86) afirma com insistência que "o limite de toda estratégia didática é o surgimento do pensamento do outro, por isso ensinar/aprender filosofia (a filosofar) é uma tarefa compartilhada". Essa também é a posição de Walter Omar Kohan (UERJ), o qual considera fundamental que o/a licenciando/a:

se sinta dentro do próprio exercício do filosofar, ou seja, que ele[/a] sinta que faz filosofia com outros, que ele[/a] seja formado fazendo filosofia com outros para que depois ele[/a] possa fazer isso com outros[/as] também já como professor[/a]... também considero fundamental que ele[/a] filosofe sobre o que significa ensinar $e$ aprender, os espaços $e$ tempo onde se pode ensinar filosofia, com quem e para que, quais os sentidos dessa tarefa... e seria bonito que nessa tarefa de pensar a si mesmo e sua prática ele[/a] possa ter como interlocutores[/as] outras pessoas que fizeram isso em outros tempos e lugares, que leia essas pessoas $e$ pense junto.

José Benedito de Almeida Jr. Também compartilha da visão de Cerletti $e$ Kohan, indicando a postura dialógica como caminho para a formação da autonomia no pensar e no agir. Questiona: “como um[/a] professor[/a] teleguiado[/a] em seu processo de formação pode ser, depois, autônomo?". Todavia, se para ele, "docentes e discentes estão em situação de igualdade de direitos, como cidadãos [...], não podemos descartar a importância do trabalho docente, de suas escolhas didáticas de conteúdos e métodos que formam parte essencial da motivação para o trabalho"; por isso, pontua Almeida Jr. que "a igualdade de direitos não deve servir para se tentar anular a liberdade de cátedra".

Por fim, sobre o primeiro dos três novos pontos prescritos para a formação do/a professor/a de Filosofia, a saber, a discussão sobre o papel formativo da Filosofia, Filipe Ceppas (UFRJ) considera "imprescindível essa dimensão mais reflexiva sobre porque eu estou fazendo o que eu estou fazendo: o que, de fato, eu contribuo na formação desse[/a] aluno[/a] que está no ensino médio? [...] Por que eu estou trabalhando filosofia com essa galera? Para que?" 19 Preocupação esta compartilhada por Lorieri: "é importante haver estudos relativos ao papel formativo da Filosofia em geral $e$ ao papel formativo do ensino de Filosofia especialmente no Ensino Médio". O próprio Lorieri já indicara preocupação com o tópico na passagem que encerra o livro $O$ papel formativo da Filosofia:

Muitas são as vozes a invocar os
benefícios formativos da Filosofia e
do filosofar. [...] A humanidade não
criou a Filosofia para nada. Ela foi
criada para atender, assim como
outras criações, às necessidades dos
seres humanos. Por ser necessária,
ela é importante na formação dos

${ }^{19}$ Continua Ceppas: "Isso é algo que eu procuro fazer articuladamente com uma revisão da literatura filosófica sobre a transmissão filosófica (desde Heráclito até Derrida ou Achille Mbembe), o que não deixa de ser uma forma do[/a] licenciando[/a] revisar o conteúdo filosófico que ele[/a] está aprendendo durante a graduação em articulação com a reflexão sobre ensino de Filosofia. Na maior parte das disciplinas ele[/a] não vai ter essa articulação". 
humanos. Que não lhes seja sonegada! (LORIERI, 2016, p. 265).

Posição semelhante defende Luizir de Oliveira, salientando, em tom enfático, que a percepção do caráter formativo da Filosofia pelos alunos e alunas faz valer o ofício docente:

A formação humanística que toda/o aquele que se volta para a Filosofia acaba por alcançar, nos mais diferentes graus, claro, deveria manterse no horizonte de todas/os nós que lidamos cotidianamente como um campo do saber tão rico, vasto, profundo, enriquecedor e libertador como a Filosofia. Se conseguirmos mostrar isso às/aos nossas/os estudantes, já terá valido a pena!

\section{Considerações Finais}

Inicio essa derradeira seção participando as palavras de Rodrigo Pelloso Gelamo (UNESP):

entendo ser urgente uma dedicação $e$ um olhar atento dos pesquisadores da filosofia para essa disciplina que, depois de 10 anos no ensino médio, ainda não se consolidou como necessária [...].Com outra urgência, não menor, penso ser necessária que a formação de professores de filosofia qualificados para entrar na sala de aula de ensino médio e universitário seja pensada de forma mais detida e dedicada.

A citação de Gelamo em alguma medida recupera a epígrafe de Dalton José Alves, na qual se afirma que as questões sobre a Filosofia e a educação filosófica nas escolas passa, necessariamente, pela discussão da formação docente. O próprio Alves, porém, salienta que muito já caminhamos nesse sentido:
Quando se brigava pela obrigatoriedade da Filosofia por lei, o tema era a justificativa para a Filosofia enquanto disciplina escolar. Depois de 2008 a questão incide em como, que é a questão mais didático-filosófica: qual a melhor forma de ter a Filosofia no currículo para que os alunos tenham o melhor aproveitamento possível. [...] Como fazer para que a Filosofia na escola seja efetivamente uma educação filosófica? [...] [Desde então assistiu-se à] ampliação do tema para a pós-graduação: o Programa do CEFET, o PROF-FILO, a abertura da ANPOF para o Ensino Médio. E tudo isto é muito positivo e deve ser ampliado.

Assistiu-se, na década de 2008 a 2018, à consolidação das iniciativas de ensino, pesquisa e extensão na área de (Filosofia do) Ensino de Filosofia ${ }^{20}$. Se, por um lado, desde 2019 o lugar da Filosofia na Educação Básica passou a ser incerto ${ }^{21}$, por outro, tem-se que o muito já produzido $e$ pensado sobre o tema nos permite alinhavar uma perspectiva formativa enquanto área. As seções precedentes procuraram fundamentar que, a despeito das respostas aqui entrelaçadas à pergunta "O que considera fundamental para formar um/a professor/a de Filosofia?" não adentrarem as

\footnotetext{
${ }^{20}$ Parte significativa desta consolidação diz respeito às produções dos/as integrantes do GT da ANPOF Filosofar e Ensinar a Filosofar. Para acesso a esse acervo, cf. VELASCO, 2020.

${ }^{21}$ Cf. Lei n. 13.415, de fevereiro de 2017, a qual substitui a obrigatoriedade da disciplina Filosofia pela inclusão obrigatória de estudos e práticas de Filosofia na Base Nacional Comum Curricular (BNCC); a Etapa do Ensino Médio da BNCC foi aprovada pelo CNE em 4 de dezembro de 2018 (disponível em: $\mathrm{http}$ //basenacionalcomum.mec.gov.br/a-base. Acesso: 14 fev. 2020).
} 
bases epistemológicas que as fundamentam, há expressivos pontos comuns nas reflexões dos/as pesquisadores/as da área sobre o assunto.

De forma sintética, há que se tomar o ensino de Filosofia como problema filosófico, indissociável, portanto, da pesquisa. Deve-se oferecer conhecimento profundo de Filosofia e de metodologias $e$ práticas de ensino de Filosofia, atentando para o trabalho com a dimensão prática desde o início e durante toda a formação docente. Uma formação que se dedica a pensar sobre o próprio valor formativo e que não se encerra com a Licenciatura entendida como "curso com nome $e$ sobrenome próprios" -, mas requer aprimoramento contínuo, abertura à alteridade e diálogo com as outras áreas de conhecimento, com a cultura, com o seu público alvo. Posturas necessárias para que o Ensino de Filosofia seja significativo e, por conseguinte, efetivamente formativo.

Não é à toa, pois, que Edgar Lyra diga que "o trabalho de formação de professores[/as] é artesanal. Cada um é um" $e$ isso demanda que enxerguemos cada uma de nossas licenciandas e cada um de nossos licenciandos, "que cada um tenha nome, tenha domicílio, tenha desejos". As dificuldades do processo de formação docente são ainda maiores se atentarmos à advertência de Filipe Ceppas (UFRJ). Sobre o "conjunto de múltiplas competências que $\mathrm{o}[/ \mathrm{a}]$ professor[/a] estagiário[/a] tem que ir construindo e que vai construindo a vida inteira quando for professor[/a]", apresentado neste artigo sob a ótica dos/as professores/as formadores/as da área, diz ele: "não acho que esse período de formação seja como um lugar em que você vai lá se apropriar de ferramentas e vai estar pronto para dar aula. Não. Você vai entrar na escola e vai penar e continuar penando até o fim da vida, dando aula para descobrir como fazer, como trabalhar".

Nesse sentido, segundo Dante Galeffi,

Um[/a] professor[/a] de filosofia deve formar-se [...] construindo o seu próprio barco para navegar no universo do conhecimento múltiplo, heterogêneo, dinâmico. Uma transformação impossível do mesmo modo como é impossível a República de Platão. Mas [...] o presente é cheio de presenças irradiantes no campo da educação filosófica e do ensino e aprendizagem da filosofia. Filosofar é um meio de resistência criadora.

Alimentada pelo diálogo com meus pares, tal como Gelamo, "reverencio os pesquisadores que nos antecederam $e$ que abriram caminhos para que pudéssemos chegar onde chegamos". Imbuída de resistência criadora, conclamo à comunidade filosófica que publicizemos nossas (irradiantes) iniciativas na área, encontrando convergências nas diferenças, fortalecendonos; enfim, reconstruindo e ressignificando a despeito de qualquer governo ou política educacional - nosso ofício de formadores $e$ formadoras de professores/as. 


\section{Referências}

CEPPAS, Filipe. Re-introduzindo a questão sobre a justificação do ensino de filosofia. In: Anais do XII Encontro Nacional de Didática e Prática de Ensino (ENDIPE). Curitiba, 2004, p. 3537-3552.

CERLETTI, Alejandro. O ensino de filosofia como problema filosófico. Tradução de Ingrid Müller Xavier. Belo Horizonte: Autêntica Editora, 2009.

CRUZ COSTA, João. A situação do ensino filosófico no Brasil. In: Panorama da História da Filosofia no Brasil. São Paulo: Cultrix, 1959.

GALLO, Silvio; KOHAN, Walter. O. Crítica de alguns lugares comuns ao se pensar a Filosofia no ensino médio. In: KOHAN, Walter O. (Org.). Filosofia no Ensino Médio. Petrópolis, RJ: Vozes, 2000.

GELAMO, Rodrigo Pelloso. O ensino da filosofia no limiar da contemporaneidade: o que faz o filósofo quando seu ofício é ser professor de filosofia? São Paulo: Cultura Acadêmica, 2009.

LORIERI, Marcos Antonio. Papel formativo da Filosofia: contribuições a partir do V Congresso da SOFELP. In: SEVERINO, Antonio J.; LORIERI, Marcos A.; GALLO, Silvio. (Org.). O papel formativo da Filosofia. Jundiaí: Paco Editorial, 2016, p. 231-265.

PAGNI, Pedro Angelo. Os limites e as discretas esperanças do ensino da filosofia: da questão da educação dos educadores aos temas relativos ao amor e à infância no pensamento contemporâneo. In: GALLO, Silvio; DANELON, Márcio; CORNELLI, Gabriele. (Org.). Ensino de Filosofia: teoria e prática. Ijuí: UNIJUÍ, 2004, p. 217-263.

TOMAZETTI, Elisete M. Filosofia no Ensino Médio e seu professor: algumas reflexões. Revista do Centro de Educação. Santa Maria, v. 27, n. 2, p. 69-75, 2002.

. Formação e Arte de viver: o que se ensina quando se ensina Filosofia? In: PAGNI, Pedro A.; BUENO, Sinésio F.; GELAMO, Rodrigo P. (Org.) Biopolítica, arte de viver e educação. Marília: Oficina Universitária; São Paulo: Cultura Acadêmica, 2012, p. 229-247.

VELASCO, Patrícia Del Nero. (Org.). Ensino de - qual? - Filosofia: ensaios a contrapelo. Marília: Oficina Acadêmica, São Paulo: Cultura Acadêmica, 2019.

. Filosofar e Ensinar a Filosofar: registros do GT da ANPOF - 2006-2018. In: VELASCO, Patrícia D. N. Filosofar e Ensinar a Filosofar: registros do GT da ANPOF - 20062018. Rio de Janeiro: NEFI Edições, 2020. - (coletivoS; 4).

Recebido em: $16 / 05 / 2020$

Aprovado em: 20/10/2020 